\title{
Circulating proteasome activity following mild head injury in children
}

\author{
Marzena Tylicka • Ewa Matuszczak • Wojciech Dębek • \\ Adam Hermanowicz $\cdot$ Halina Ostrowska
}

Received: 26 February 2014 / Accepted: 24 March 2014 / Published online: 4 April 2014

(C) The Author(s) 2014. This article is published with open access at Springerlink.com

\begin{abstract}
Purpose The aim of the study is to characterize changes in circulating proteasome (c-proteasome) activity following mild traumatic brain injury in children.

Methods Fifty children managed at the Department of Pediatric Surgery because of concussion - mild head injury was randomly included into the study. The children were aged 11 months to 17 years (median $=10.07+-1.91$ years). Plasma proteasome activity was assessed using Suc-Leu-Leu-ValTyr-AMC peptide substrate, $2-6 \mathrm{~h}, 12-16 \mathrm{~h}$, and 2 days after injury. Twenty healthy children admitted for planned inguinal hernia repair served as controls.

Results Statistically significant elevation of plasma cproteasome activity was noted in children with mild head injury 2-6 h, 12-16 h, and 2 days after the injury.

Conclusions Authors observed a statistically significant upward trend in the c-proteasome activity between 2-6 and 12$16 \mathrm{~h}$ after the mild head injury, consistent with the onset of the symptoms of cerebral concussion and a downward trend in the c-proteasome activity in the plasma of children with mild head injury between $12-16 \mathrm{~h}$ and on the second day after the injury, consistent with the resolving of the symptoms of cerebral concussion. Further studies are needed to demonstrate that the proteasome activity could be a prognostic factor, which can help in further diagnostic and therapeutic decisions in patients with head injury.
\end{abstract}

Keywords Mild head injury $\cdot$ Concussion $\cdot$ Head injury · Children $\cdot$ Circulating proteasome activity $\cdot$ Plasma

E. Matuszczak $(\bowtie) \cdot$ W. Dębek $\cdot$ A. Hermanowicz $\cdot$ H. Ostrowska Department of Pediatric Surgery, Medical University of Białystok, 15-274 Białystok, Poland

e-mail: ewamat@tlen.pl

M. Tylicka

Department of Biophysics, Medical University of Białystok,

Mickiewicza 2A, 15-089 Białystok, Poland

\section{Introduction}

Head trauma occurs commonly in children. Most children with head trauma are young, male, and have a mild injury [31]. Mild head injury is generally associated with symptoms such as a brief loss of consciousness, disorientation, or vomiting. Patients with mild head injury usually have GCS scores of 13 to 15 , measured approximately $30 \mathrm{~min}$ after the injury $[30,31]$. The onset of impairment is rapid, but usually short-lived, and generally resolves spontaneously. Still, head injury is the most common cause of death and disability during childhood [19, 30, 31].

Consequently, children after mild head injuries are commonly admitted to emergency or surgical departments, overdiagnosed, and hospitalized. This large group of patients produces significant costs to the public health system. Therefore, new biochemical markers of mild head injuries are needed.

Ubiquitin-proteasome system is the principal enzyme system responsible for protein degradation, which has been reported to be abundantly expressed in the various cell types of the central nervous system $[9,28]$. The addition of polyubiquitin chains to a protein results in its translocation to the proteasome, a large multi-subunit protease, which then results in its degradation. Proteasome catalytic function not only degrades most cytosolic proteins, but plays an essential role in numerous cellular processes including cell cycle programming, transcriptional control, signal transduction, and the elimination of damaged proteins [37]. The clearance of damaged proteins is indispensable in order to provide the necessary conditions for cellular repair and plasticity. Induction of proteasome has been reported after different traumatic stressors, such as hyperoxia, radiation, or oxidative damage $[1,32]$. It is known that the oxidized proteins are tagged for degradation, and that activity of proteasome complex can be induced by oxidative protein damage in cell culture [32]. Recent in vitro study reports have demonstrated ubiquitin- 
proteasome enzyme system playing an essential role in rapid phase of ischemic preconditioning of cultured neurons [21, 22]. Also, ubiquitin-proteasome system activation is one of the important mechanisms regulating the cell death pathways in ischemic neurons [33]. Study by Szabo et al showed that experimental brain trauma elevates the levels of protein oxidation in the injured cerebral cortex. Correlation analysis showed that protein oxidation was positively associated with proteasome activity [32].

Moreover, patients with head injury exhibit negative nitrogen balance, enhanced rates of whole body protein breakdown, and a sustained rise in urinary 3-methylhistidine excretion, an index of muscle myofibrillar protein breakdown [18]. Overexpression of multiple components of the ubiquitinproteasome proteolytic pathway in muscle biopsies from head trauma patients strongly suggests that this pathway is involved in the breakdown of contractile protein in humans [18].

The purpose of this novel human study was to characterize changes following mild head injury in children in the circulating $20 \mathrm{~S}$ proteasome activity.

\section{Methods and materials}

\section{Patients}

The study was approved by the local Ethics Committee as an audit of a clinically agreed-upon protocol of investigation and treatment. All parents of the patients gave informed consent for both clinical and biochemical follow-up. The study population comprised 50 children admitted due to mild head injury to Department of Pediatric Surgery of Medical University of Bialystok, between 2010 and February 2014. Patients were randomly included in the study. Patients were aged 11 months to 17 years (median $=10.07+-1.91$ years). There were 19 girls and 31 boys. Falls were the most common mechanism of injury for our patients sustaining mild head injury, followed by motor vehicle crashes, pedestrian and bicycle accidents, and sports-related trauma. The diagnosis of mild head injury was based upon the following symptoms: loss of consciousness, amnesia, vomiting, severe headache, GCS score 13-15, and normal head CT. Patients with mild head injury were managed according to the conventional lines of head injury treatment in our department.

Exclusion criteria were GCS score below 13, abnormal head CT, hospital admission later than $6 \mathrm{~h}$ after injury, severe preexisting infections, and other diseases that required longterm medication.

Twenty healthy children aged $1-14$ years (median $=4.36+$ -2.03 years), admitted to the Department of Pediatric Surgery for planned inguinal hernia repairs between 2010 and 2012 (6 girls, 14 boys), served as controls. Exclusion criteria were hospital admission later than $6 \mathrm{~h}$ after injury, severe preexisting infections, and diseases that required longterm medication.

Methods

Venous blood samples (1-2 ml) were drawn after admission, 2-6, and 12-16 $\mathrm{h}$ after the injury and in the morning of the subsequent 2 days along with the routine laboratory work-up. Blood samples were collected in plasma test tubes (EDTA tubes), plasma prepared according to the standard hospital procedures and stored at $-80{ }^{\circ} \mathrm{C}$ until further analysis. After all blood samples were collected and patient data recorded, circulating $20 \mathrm{~S}$ proteasome activity in the plasma was determined with the investigators blinded to the patient-related data.

The thawed plasma samples were centrifuged to remove fibrinogen, and then, each sample was diluted to the protein concentration of $5.0 \mathrm{mg} / \mathrm{mL}$ with $100 \mathrm{mmol} / \mathrm{L}$ Tris- $\mathrm{HCl}(\mathrm{pH} 7.5)$ supplemented with inhibitors of other proteases: ethylene diamine tetraacetic acid (EDTA, $1 \mathrm{mmol} / \mathrm{L}$ ), trans-epoxysuccinylleucylamide (4-guanidino)butane (E-64, $10 \mu \mathrm{mol} / \mathrm{L})$, and pepstatin $(1 \mu \mathrm{mol} / \mathrm{L})$ (Sigma, USA). Total protein concentration in plasma samples was determined using the Bio-Rad assay reagent with bovine serum albumin as the standard.

The proteasome activity in the plasma was measured using the assay designed to measure chymotrypsin-like protease activity (ChT-L) of proteasomes using the fluorogenic peptide substrate the Suc-Leu-Leu-Val-Tyr-AMC in the presence of sodium dodecyl sulfate (SDS) as an artificial proteasome activator. The reaction mixture (total volume, $30 \mu \mathrm{L}$ ) contained $100 \mathrm{mmol} / \mathrm{L}$ Tris-HCl buffer $(1 \mathrm{mmol} / \mathrm{L}$ EDTA, EGTA, $0.05 \%$ SDS, pH 7.5), and $10 \mu \mathrm{L} \mathrm{0,5} \mathrm{mmol/L} \mathrm{Suc-}$ Leu-Leu-Val-Tyr-AMC substrate. Ten microliters of nonactivated plasma sample or $10 \mu \mathrm{L}$ of plasma sample activated for $15 \mathrm{~min}$ at room temperature with $10 \%$ SDS added to the reaction mixture. To confirm the specificity of the assay, the plasma was preincubated with the selective proteasome inhibitor epoxomicin $(1.0 \mu \mathrm{mol} / \mathrm{L})$ for $15 \mathrm{~min}$ before the addition of a substrate. The samples were incubated at $37^{\circ} \mathrm{C}$ for 30 $60 \mathrm{~min}$, since during this time, a linear relation between time and product generation was obtained. After incubation, the reaction was stopped by the addition of $1 \mathrm{~mL}$ of $100 \mathrm{mmol} / \mathrm{L}$ monochloroacetate $-30 \mathrm{mmol} / \mathrm{L}$ sodium acetate, and the samples were centrifuged to remove any insoluble material. Fluorescence of the released $\mathrm{AMC}$ was determined at $380 \mathrm{~nm}$ excitation and $460 \mathrm{~nm}$ emission wavelength in a Hitachi F-2000 fluorimeter. The $20 \mathrm{~S}$ proteasome ChT-L activity was calculated from the differences between the fluorescence in the sample incubated with the substrate and the sample incubated with $0.1 \%$ dimethyl sulfoxide (DMSO). One unit of the $20 \mathrm{~S}$ proteasome ChT-L activity was expressed as the amount of AMC released from the substrate per minute ( $\mathrm{pmol} / \mathrm{min}$ ). All assays were performed in triplicates. 
For identification of $20 \mathrm{~S}$ proteasome antigen, a plasma sample $(20 \mu \mathrm{g}$ of total protein per line) was electrophoresed by SDS-polyacrylamide gel electrophoresis (PAGE) in a $10 \%$ separation gel under reducing conditions, and then proteins were electroblotted onto nitrocellulose membranes. The nitrocelluloses were incubated for $1 \mathrm{~h}$ with the monoclonal antibody reacting with the human $\beta 5$ subunit (C2) of the $20 \mathrm{~S}$ proteasome (Affiniti Research Products Ltd., UK). The immunoreactive proteins were visualized with an alkaline phosphate-conjugated anti-rabbit IgG as the secondary antibody and p-nitrophenyl phosphate as the phosphatase substrate (Sigma, USA).

\section{Statistics}

Proteasome activity is described as median with 25 th and 75 th percentiles. All data are presented along with the exact number of measurements. Because the proteasome activity in the plasma of our patients did not pass the normality test, the Mann-Whitney $U$ test and the Kruskal-Wallis $H$ test were used to compare differences between groups. Statistical analyses were calculated with the STATISTICA PL release 10.0 Program. A two-tailed $p<0.05$ was considered significant.

\section{Results}

The circulating proteasome (c-proteasome) activity was detectable in all plasma specimens from patients and controls.

In the group of our patients with mild head injury, the cproteasome activity $2-6 \mathrm{~h}$ after the injury, $12-16 \mathrm{~h}$ after injury, and 2 days after injury were above the range of activity measured in controls which was statistically significant (Fig. 1). There was an upward trend in the c-proteasome activity between 2-6 and 12-16 h after the injury, consistent with the onset of the symptoms of cerebral concussion and a downward trend in the c-proteasome activity in the plasma of children with mild TBI between 12-16 h and on the second day after the injury, consistent with the resolving of the symptoms of cerebral concussion. The c-proteasome activity was not associated with age or sex ( $p>0.05$, data not shown).

\section{Discussion}

Mild head injury usually occurs due to contact or accelerationdeceleration forces. The goal of the evaluation of children with head trauma is to identify those who may require immediate intervention or close follow-up. Although associated intracranial injury occurs in a small percentage of those children who have a normal neurologic examination at presentation, it must be recognized in order to prevent deterioration and subsequent morbidity or mortality [19, 30, 31].
Mild head injury causes a reduction in cognitive capacity $[27,29]$, possibly due to deterioration in the molecular substrates that support synaptic plasticity and function. Most forms of synaptic plasticity involve protein synthesis and limited protein degradation [11], which are under the spectrum of the action of proteasome complex. The proteasome system is responsible for the degradation of altered cellular proteins, including those modified by reactive oxygen species. Oxidized proteins are tagged for degradation either by the change of hydrophobicity or by ubiquitination, such that residual amino acids can be recycled for protein synthesis [6]. In our study, we wanted to check the hypothesis that c-proteasome activity in the plasma of children with minor head injury is associated with the onset and resolving of symptoms of cerebral concussion.

Several lines of evidence strongly suggest the ubiquitinproteasome cascade is involved in responses to CNS stress or injury. Weih et al demonstrated that proteasome activation is needed for the proteolysis of oxidized proteins in cortical neurons under glucose and oxygen deprivation [34]. Another study showed that enhancement of proteasome activity potentially reduces neuronal vulnerability to oxidative injury [35]. A transgenic mouse study indicated that loss of an individual proteasome subunit_LMP2 — alters mice brain function [20]. Using antibodies that recognize the entire $20 \mathrm{~S}$ proteasome complex, Mengual et al [23] found that the proteasome is ubiquitously, although not homogeneously, expressed in rat $\mathrm{CNS}$, and that subcellular distribution is localized to cytoplasmic, nuclear, dendritic, and axonal processes, and in synaptic boutons. Also in the group of our patients with mild head injury, the c-proteasome activity 2-6 h after the injury, $12-$ $16 \mathrm{~h}$ after injury, and 2 days after injury were above the range of activity measured in controls which was statistically significant.

Earlier findings suggested that systemic 20S proteasome concentrations reflect cellular damage independent of the underlying cause of the disease and circulating proteasomes might be a useful biomarker to assess disease severity or progression $[6,10,17]$. In our study, we used assay of plasma 20S proteasome ChT-L activity for the measurement of circulating proteasomes. Several authors confirmed the specificity of this assay with highly selective proteasome inhibitors [25]. The most common method of detecting circulating proteasomes in plasma or serum is the enzyme-linked immunoabsorbent assay (ELISA) test employing antibodies directed against the constitutive $\alpha 6$ (C2) subunits of the $20 \mathrm{~S}$ proteasome [2, 5]. ELISA-based assay does not provide information about circulating proteasome activity in the plasma, since only intact $20 \mathrm{~S}$ proteasome complexes, but not subunit fragments, are enzymatically active. The method allows for the detection of only the intact $20 \mathrm{~S}$ proteasome complexes, since free catalytic subunits are enzymatically inactive, so $20 \mathrm{~S}$ proteasome ChT-L activity assay in plasma is a good alternative to ELISA for the measurement of circulating proteasomes [2, 5]. 
Fig. 1 Circulating proteasome activity in the plasma of children, $2-6 \mathrm{~h}(1, n=50), 12-16 \mathrm{~h}$

$(2, n=45), 2$ days $(3, n=41)$ after mild head injury and in control group

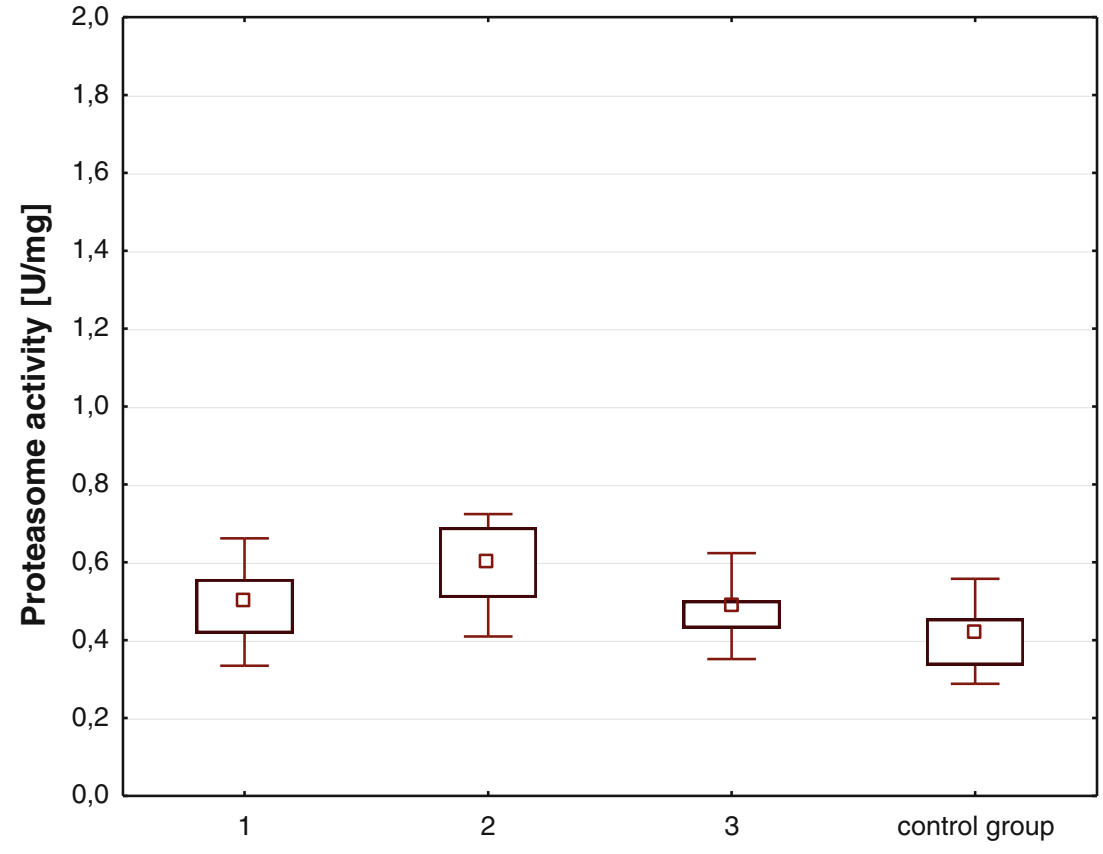

A decline in proteasome function is believed to underline many neurodegenerative diseases [12], where impaired function of the proteasomes has been proposed to contribute to the pathogenesis of degenerative diseases because of an accumulation of abnormal proteins [2, 7, 13, 14]. Impairment in the ubiquitin-proteasomal system also has been suggested as one of the underlying mechanisms of Parkinson's and Alzheimer's disease [3, 15]. Study of Alzheimer disease autopsy brain samples suggested that $19 \mathrm{~S}$ and $20 \mathrm{~S}$ proteasome subunits are localized in neurons [15].

In contrast to its role as pathogenic factor in neurodegenerative diseases, limitation of protein turnover after cellular damage would rather support regenerative processes. Increasing evidence indicates that reversible proteasome inhibitors can be therapeutic agents even neuroprotective during ischemic brain injury [36, 38]. Reduction of proteasome function is seen as key for reducing CNS damage from acute traumatic brain injury and stroke. Several studies have demonstrated that suppression of function by proteasome inhibitor administration leads to better outcome from CNS injury [8, 35, 38]. In our experiments, we observed an upward trend in the c-proteasome activity between 2-6 and 12-16 h after the injury, consistent with the onset of symptoms of cerebral concussion and a downward trend in the cproteasome activity in the plasma of children with mild head injury between $12-16 \mathrm{~h}$ and 2 days after the injury, consistent with the resolving of the symptoms of cerebral concussion.

Another group of proteasome family - immunoproteasomes have been detected in human brains and indicate that immunoproteasomes participate in normal neuronal physiology [4, 24, 26]. A study of human brain injury by Majetschak et al, showed a progressive rise of CSF ubiquitin levels in traumatic brain injury patients who succumbed to their injuries compared with those who survived [16].

Our observations are the first to show an increase in circulating proteasome activity in the plasma in children hospitalized because of mild head injury. Our results also demonstrate, that molecular changes affecting protein metabolism, occur soon after head injury, and there is a downward trend in the cproteasome activity in the plasma of children with mild head injury along with the resolving of the symptoms of the cerebral concussion.

\section{Conclusions}

Authors observed a statistically significant upward trend in the c-proteasome activity between 2-6 and 12-16 after the mild head injury, consistent with the onset of the symptoms of cerebral concussion, and a downward trend in the c-proteasome activity in the plasma of children with mild head injury between $12-16 \mathrm{~h}$ and on the second day after the injury, consistent with the resolving of the symptoms of cerebral concussion. Further studies are needed to demonstrate that the proteasome activity could be a prognostic factor, which can help in further diagnostic and therapeutic decisions in patients with head injury. 
Open Access This article is distributed under the terms of the Creative Commons Attribution License which permits any use, distribution, and reproduction in any medium, provided the original author(s) and the source are credited.

\section{References}

1. Chambellan A, Cruickshank PJ, McKenzie P, Cannady SB, Szabo K, Comhair SA, Erzurum SC (2006) Gene expression profile of human airway epithelium induced by hyperoxia in vivo. Am J Res Cell Mol Biol 35:424-435

2. Davies KJ (2001) Degradation of oxidized proteins by the $20 \mathrm{~S}$ proteasome. Biochimie 83:301-310

3. Dawson TM, Dawson VL (2003) Molecular pathways of neurodegeneration in Parkinson's disease. Science 302:819-822

4. Diaz-Hernandez M, Hernandez F, Martin-Aparicio E, Gomez-Ramos P, Moran MA, Castano JG, Ferrer I, Avila J, Lucas JJ (2003) Neuronal induction of the immunoproteasome in Huntington's disease. J Neurosci 23:11653-11661

5. Dutaud D, Aubry L, Henry L, Levieux D, Hendil KB, Kuehn L, Bureau JP, Ouali A (2002) Development and evaluation of a sandwich ELISA for quantification of the $20 \mathrm{~S}$ proteasome in human plasma. J Immunol Methods 260:183-19

6. Egerer K, Kuckelkorn U, Rudolph PE, Ruckert JC, Dorner T, Burmester GR, Kloetzel PM, Feist E (2002) Circulating proteasomes are markers of cell damage and immunologic activity in autoimmune diseases. J Rheumatol 29:2045-2052

7. Halliwell B (2002) Hypothesis: proteasomal dysfunction: a primary event in neurodegeneration that leads to nitrative and oxidative stress and subsequent cell death. Ann NY Acad Sci 962:182-194

8. Henninger N, Sicard KM, Bouley J, Fisher M, Stagliano NE (2006) The proteasome inhibitor VELCADE reduces infarction in rat model of focal cerebral ischemia. Neurosci Lett 398:300-305

9. Herrmann J, Lerman LO, Lerman A (2007) Ubiquitin and ubiquitinlike proteins in protein regulation. Circ Res 100:1276-1291

10. Jakob C, Egerer K, Liebisch P, Turkmen S, Zavrski I, Kuckelkorn U, Heider U, Keiser M, Fleissner C, Sterz J, Kleeberg L, Feist E, Burmester GR, Kloetzel PM, Sezer O (2007) Circulating proteasome levels are an independent prognostic factor for survival in multiple myeloma. Blood 109:2100-2105

11. James AB, Conway AM, Morris BJ (2005) Genomic profiling of the neuronal target genes of the plasticity-related transcription factorZif268. J Neurochem 95:796-810

12. Keller JN, Gee J, Ding Q (2002) The proteasome in brain aging. Ageing Res Rev 1:279-293

13. Keller JN, Hanni KB, Markesbery WR (2000) Impaired proteasome function in Alzheimer's disease. J Neurochem 75:997-1013

14. Kloetzel PM (2001) Antigen processing by the proteasome. Nat Rev Mol Cell Biol 2:179-187

15. Lam YA, Pickart CM, Alban A, Landon M, Jamieson C, Ramage R, Mayer RJ, Layfield R (2000) Inhibition of the ubiquitin-proteasome system in Alzheimer's disease. Proc Natl Acad Sci U S A 97:9902-9906

16. Majetschak M, King DR, Krehmeier U, Busby LT, Thome C, Vajkoczy S, Proctor K (2005) Ubiquitin immunoreactivity in cerebrospinal fluid after traumatic brain injury: clinical and experimental findings. Crit Care Med 33:1589-1594

17. Majetschak M, Perez M, Sorell LT, Lam J, Maldonado ME, Hoffman RW (2008) Circulating 20S proteasome levels in patients with mixed connective tissue disease and systemic lupus erythematosus. Clin Vac Immunol 15:1489-1493

18. Mansoor O, Beaufrere B, Boirie Y, Ralliere C, Taillandier D, Aurousseau E, Schoeffler P, Arnal M, Attaix D (1996)
Increased mRNA levels for components of the lysosomal, $\mathrm{Ca}^{2+}$-activated, and ATP-ubiquitin-dependent proteolytic pathways in skeletal muscle from head trauma patients. Proc Natl Acad Sci U S A 93:2714-2718

19. Marcin JP, Pollack MM (2002) Triage scoring systems, severity of illness measures, and mortality prediction models in pediatric trauma. Crit Care Med 30(11):S457

20. Martin S, Gee JR, Bruce-Keller AJ, Keller JN (2004) Loss of an individual proteasome subunit alters motor function but not cognitive function or ambulation in mice. Neurosci Lett 357:76-78

21. Meller R, Mameron JA, Torrey DJ, Clayton CE, Ordonez AN, Henshall DC, Minami M, Schindler CK, Saugstad JA, Simon RP (2006) Rapid degradation of Bim by the ubiquitin-proteasome pathway mediates short-term ischemic tolerance in cultured neurons. $\mathrm{J}$ Biol Chem 281:7429-7436

22. Meller R, Thompson SJ, Lusardi TA, Ordonez AN, Ashley MD, Jessick V, Wang W, Torrey DJ, Henshall DC, Gafken PR, Saugstad JA, Xiong ZG, Simon RP (2008) Ubiquitin proteasome-mediated synaptic reorganization: a novel mechanism underlying rapid ischemic tolerance. J Neurosci 28:50-59

23. Mengual E, Arizti P, Rodrigo J, Gimenez-Amaya JM, Castano JG (1996) Immunohistochemical distribution and electron microscopic subcellular localization of the proteasome in the rat CNS. J Neurosci 16:63316341

24. Mishto M, Bellavista E, Santoro A, Stolzing A, Ligorio C, Nacmias B, Spazzafumo L, Chiappelli M, Licastro F, Sorbi S, Pession A, Ohm T, Grune T, Franceschci C (2006) Immunoproteasome and LMP2 polymorphism in aged and Alzheimer's disease brains. Neurobiol Aging 27:54-66

25. Ostrowska H, Hempel D, Holub M, Sokolowski J, Kloczko J (2008) Assessment of circulating proteasome chymotrypsin-like activity in plasma of patients with acute and chronic leukemias. Clin Biochem 41:1377-1383

26. Piccinini M, Mostert M, Croce S, Baldovino S, Popotti M, Rinaudo MT (2003) Interferon-gamma-inducible subunits are incorporated in human brain 20S proteasome. J Neuroimmunol 135:135-140

27. Rees L, Marshall S, Hartridge C, Mackie D, Weiser M (2007) Cognitive interventions post acquired brain injury. Brain Inj 21: 161-200

28. Rehni AK, Singh TG, Behl N, Arora S (2010) Possible involvement of ubiquitin proteasome system and other proteases in acute and delayed aspects of ischemic preconditioning of brain mice. Biol Pharm Bull 33:1953-1957

29. Royo NC, LeBold D, Magge SN, Chen I, Hausprung A, Cohen AS, Watson DJ (2007) Neurotrophin-mediated neuroprotection of hippocampal neurons following traumatic brain injury is not associated with acute recovery of hippocampal function. Neuroscience 148: $359-370$

30. Schutzman SA, Barnes P, Duhaime AC, Greenes D, Homer C, Jaffe D, Lewis RJ, Luerssen TG, Schunk J (2001) Evaluation and management of children younger than two years old with apparently minor head trauma: proposed guidelines. Pediatrics 107(5):983

31. Schutzman SA, Greenes DS (2001) Pediatric minor head trauma. Ann Emerg Med 37:65

32. Szabo Z, Ying Z, Radak Z, Gomez-Pinilla F (2010) Voluntary exercise may engage proteasome function to benefit the brain after trauma. Brain Res 1341:25-31

33. Verma R, Deshaies RJ (2000) A proteasome howdunit: the case of the missing signal. Cell 101:341-344

34. Weih M, Schmitt M, Gieche J, Harms C, Ruscher K, Dirnagl U, Grune T (2001) Proteolysis of oxidized proteins after oxygenglucosem deprivation in rat cortical neurons is mediated by the proteasome. J Cereb Blood Flow Metab 21:1090-1096

35. Willians AJ, Dave JR, Tortella FC (2006) Neuroprotection with the proteasome inhibitor MLN519 in focal ischemic brain injury: relation to nuclear factor kappaB (NF-kappaB), 
inflammatory gene expression, and leukocyte infiltration. Neurochem Int 49:106-112

36. Williams AJ, Hale SL, Moffett JR, Dave JR, Elliott PJ, Adams J, Tortella FC (2003) Delayed treatment with MLN519 reduces infarction and associated neurologic deficit caused by focal ischemic brain injury in rats via anti-inflammatory mechanisms involving nuclear factor-kappaB activation, gliosis, and leukocyte infiltration. J Cereb Blood Flow Metab 23:75-97
37. Yao X, Liu J, McCabe J (2008) Alterations of cerebral cortex and hippocampal proteasome subunit expression and function in a traumatic brain injury rat model. J Neurochem 104:353-363

38. Zhang L, Zhang ZG, Zhang RL, Lu M, Adams J, Elliot PJ, Chopp M (2001) Postischemic (6-Hour) treatment with recombinant human tissue plasminogen activator and proteasome inhibitor PS-519 reduces infarction in a rat model of embolic focal cerebral ischemia. Stroke 32:2926-2931 